\title{
Association of SNPs in the intergenic region of OCT2 and OCT3 with short-term efficiency of metformin monotherapy in the Type 2 Diabetes patients.
}

\author{
BIOMEDICAL Jānis Kloviṇš ${ }^{1}$, Ineta Kalnina ${ }^{1}$, Kristine Geldnere ${ }^{2,3}$, Ilze Konrāde ${ }^{4}$, Liene Nikitina-Zake ${ }^{1}$, \\ RESEARCH AND STUDY \\ Davids Fridmanis ${ }^{1}$, Raitis Peculis ${ }^{1}$, Soveiga Grinberga ${ }^{5}$, OsvaldsPugovics ${ }^{5}, \&$ Valdis Pīrāgs ${ }^{2,3}$ \\ CENTRE

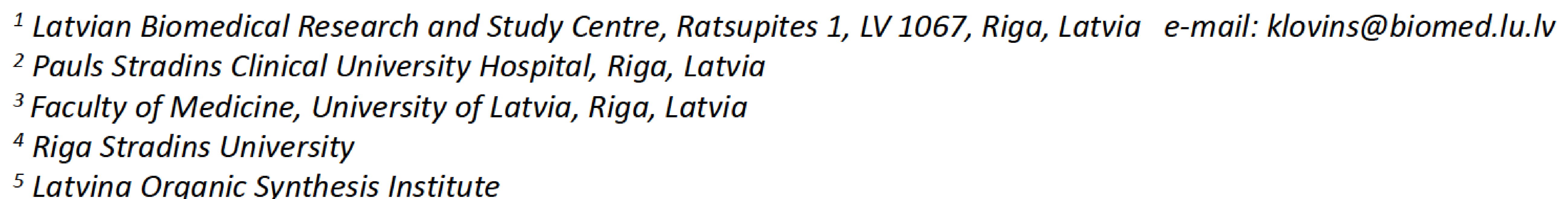

\section{Introduction}

High variability in clinical response to metformin is often observed in type 2 diabetes (T2D) patients and it highlights the need for identification of genetic components affecting the efficiency of metformin therapy. Majority of pharmacogenetic studies of metformin response have focused on genetic variability of individual candidate transporters for metformin such as OCTs and MATEs. Aim of this study is to evaluate the role of systematically selected tagSNPs from genomic regions coding for six metformin transporter genes with respect to the short-term efficiency.

\section{Methods}

102 tagSNPs in 6 metformin transporter coding genes SLC22A1, SLC22A2, SLC22A3, SLC47A1, SLC47A2 and SLC29A4(coding for OCT1, OCT2, OCT3, MATE1, MATE2 and PMAT, respectively) were genotyped in the group of 102 T2D patients treated with metformin monotherapy for 3 months. Pharmacokinetic study in 15 healthy participants was conducted to investigate the effects of identified polymorphisms on pharmacokinetics of metformin. Genotyping was done using GoldenGate Genotyping Assay with VeraCode technology (Illumina, Inc.). Logistic regression was used to estimate association of SNPs with nonresponsiveness to metformin treatment using number of cofactors (age, sex, BMI, time between HbA1c measurements, dose of metformin, level of physical activity, diet and regularity of drug intake)

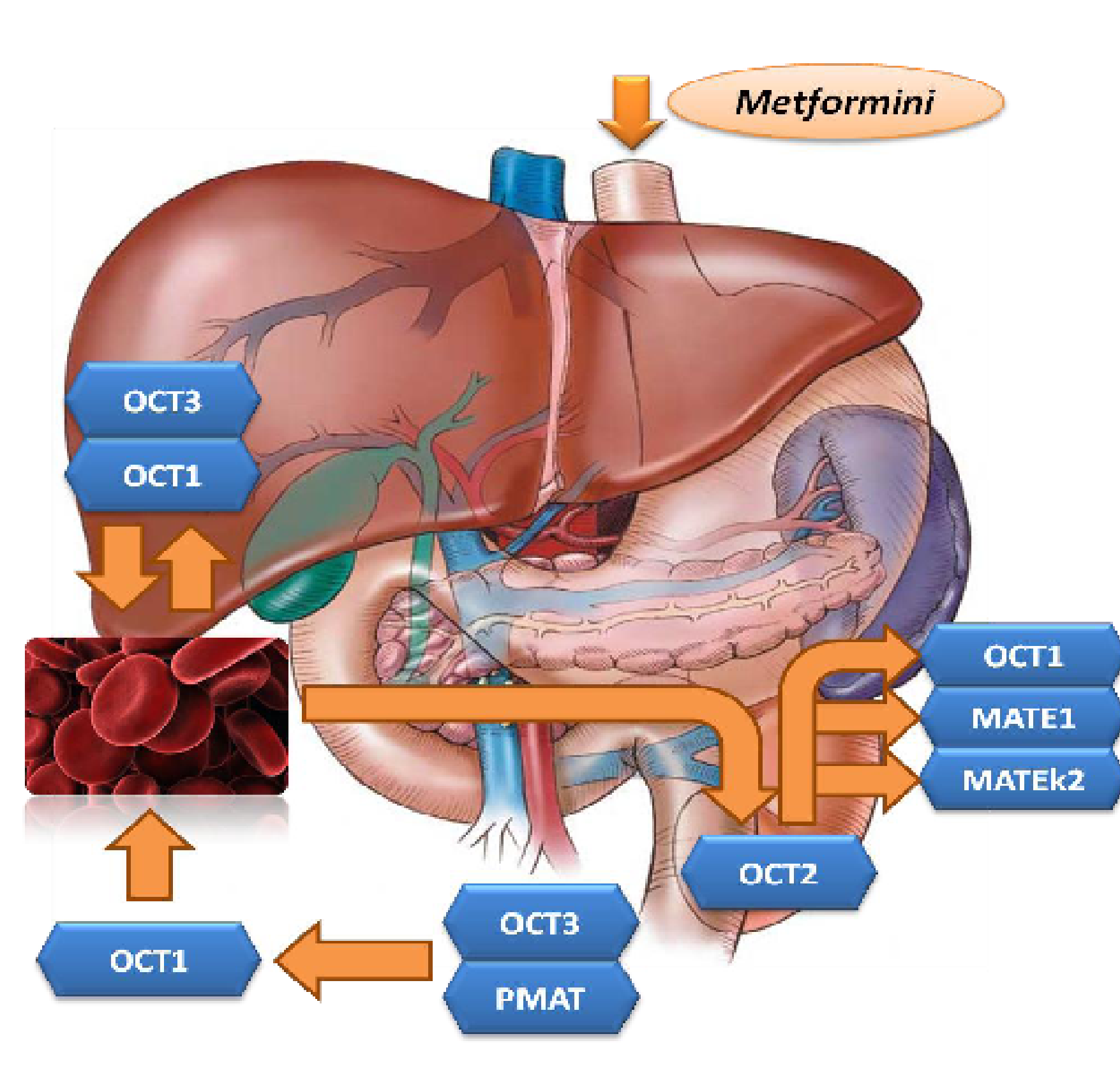

Table 1. Ccharacteristics of the study group

Figure 1. Solute carriers responsible for transport of the metformin

\begin{tabular}{|c|c|}
\hline Characteristics & $\begin{array}{l}\text { T2D patients } \\
(n=102)\end{array}$ \\
\hline Male, $\mathrm{n}(\%)$ & $33(32.4)$ \\
\hline Female, $n(\%)$ & 69(67.6) \\
\hline Mean age $\pm S D$, years & $59.7 \pm 10.6$ \\
\hline Mean $\mathrm{BMI} \pm \mathrm{SD}, \mathrm{kg} / \mathrm{m}^{2}$, baseline & $33.8 \pm 4.8$ \\
\hline Creatinine clearance $\pm \mathrm{SD}, \mathrm{mL} / \mathrm{min}$ & $120.1 \pm 43.7$ \\
\hline Dose of metformin $\pm \mathrm{SD}, \mathrm{mg} /$ per day & $1525.0 \pm 533.5$ \\
\hline Non-responders $\mathrm{n}, \%$ & $18(17.6)$ \\
\hline Days between $\mathrm{HbA} 1 \mathrm{c}$ measurments $\pm \mathrm{D}$ & $95.5 \pm 9.0$ \\
\hline HbA1c $\pm S D, \%$, baseline & $7.4 \pm 1.5$ \\
\hline HbA1c $\pm S D, \%$, after treatment, $\%$ & $6.5 \pm 0.6^{a}$ \\
\hline Decrease of $\mathrm{HbA1c} \pm \mathrm{SD}$, after treatment, $\%$ & $0.9 \pm 1.3$ \\
\hline
\end{tabular}

Results

In the group of 102 T2D patients, minor alleles of rs3119309 (OCT2/SLC22A2), rs7757336 (OCT3/SLC22A2) and rs2481030 (OCT2/SLC22A3) were significantly associated with metformin inefficiency $(\mathrm{P}=1.849 \times 10-6$ to $2.663 \times 10-5)$.Carriers of risk alleles were 8.4 times more likely to exhibit non-responder phenotype than participants with wild type alleles.

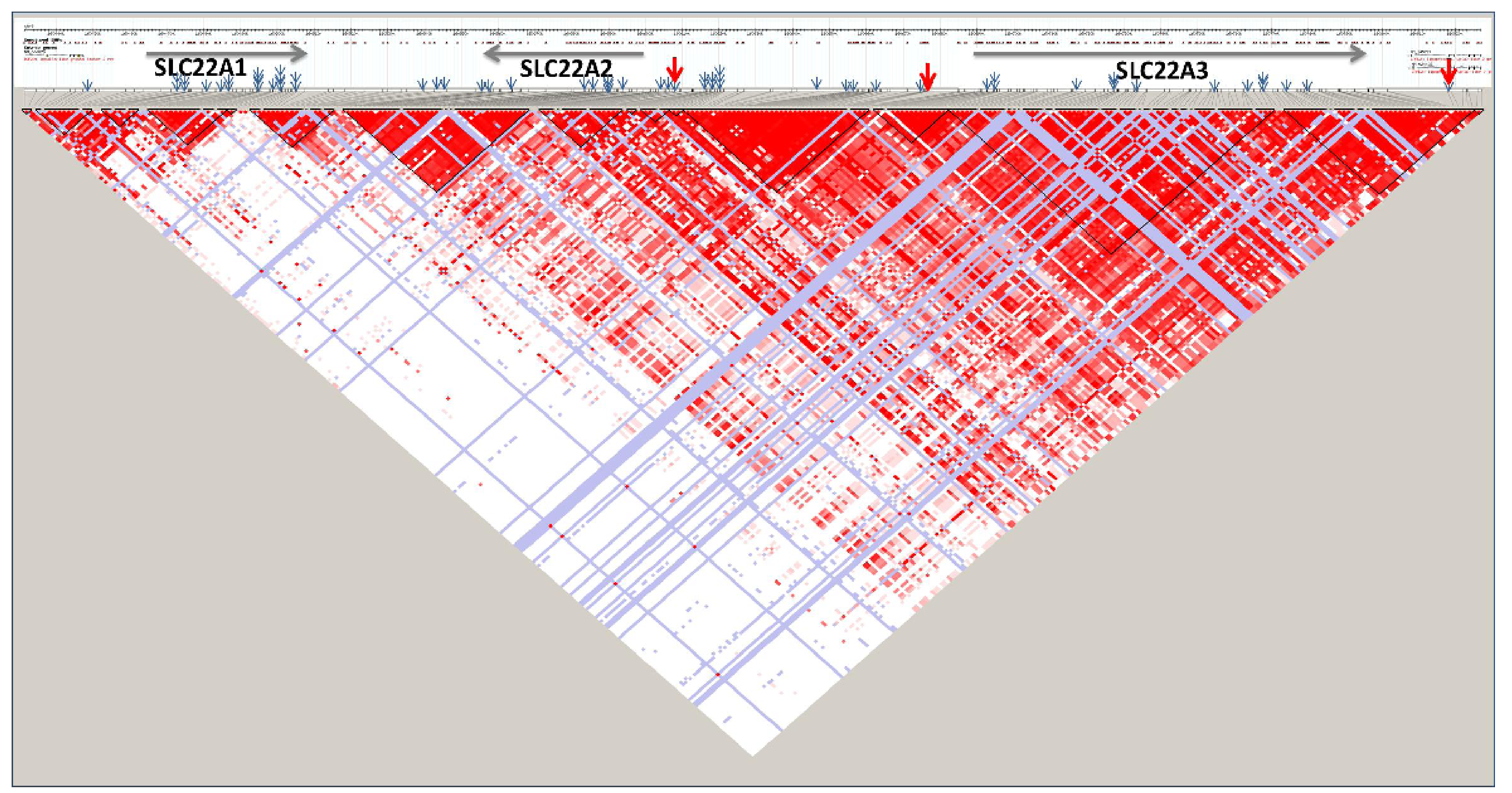

Figure 2. Haploblock structure and SNPs selected for genotyping in OCT1-3 locus
Table 2. SNPs associated with metformin efficiency

\begin{tabular}{|c|c|c|c|c|c|}
\hline \multirow[b]{2}{*}{ SNP } & \multicolumn{2}{|c|}{ Genotype number } & \multirow{2}{*}{$\begin{array}{c}\text { OR } \\
{[95 \% \mathrm{CI}]^{\mathrm{a}}}\end{array}$} & \multirow[b]{2}{*}{$\mathbf{P}^{\mathbf{a}}$} & \multirow[b]{2}{*}{ Pperm $^{b}$} \\
\hline & $\begin{array}{c}\text { Non- } \\
\text { responders }\end{array}$ & Responders & & & \\
\hline rs7757336 & $2 / 9 / 7$ & $0 / 14 / 70$ & $50.360[5.998-422.900]$ & $3.06 * \mathrm{e}^{-4}$ & 0.004 \\
\hline rs3119309 & $1 / 8 / 9$ & $0 / 9 / 75$ & $26.580[4.631-152.500]$ & $2.34 * \mathrm{e}^{-4}$ & 0.003 \\
\hline rs2481030 & $10 / 7 / 1$ & $8 / 38 / 38$ & $13.700[3.435-54.670]$ & $2.09 * \mathrm{e}^{-4}$ & 0.002 \\
\hline
\end{tabular}

Pharmacokinetic study indicated that group of people carrying at least one of the rs3119309, rs7757336 and rs2481030 rare alleles had significantly reduced AUC $\infty$ of plasma metformin compared to reference (wt) group.

Table 3. Pharmacokinetics parameters of 15 healthy participants after a single dose of ora administration of $\mathbf{5 0 0 ~} \mathbf{m g}$ Metforminin. Risk group = carriers of rs2481030 orrs7757336

\begin{tabular}{|c|c|c|c|}
\hline \multirow[b]{2}{*}{ Characteristics } & \multicolumn{3}{|c|}{ Comparison of genotype groups } \\
\hline & $\begin{array}{c}\text { Reference, } \\
\quad \mathrm{n}=8\end{array}$ & $\begin{array}{c}\text { Risk group, } \\
\mathbf{n}=7\end{array}$ & Pvalues $^{\mathrm{a}}$ \\
\hline Weight, kg, SD & $69.13 \pm 15.38$ & $79.43 \pm 9.88$ & 0.154 \\
\hline Age, SD & $24.88 \pm 3.27$ & $30.14 \pm 6.04$ & 0.052 \\
\hline Creatinine clearance, $\mathrm{mL} / \mathrm{min} / 1.73 \mathrm{~m}, \mathrm{SD}$ & $127.65 \pm 13.26$ & $126.33 \pm 11.91$ & 0.843 \\
\hline Plasma MF AUC , mghl-1 & $6.32 \pm 1.84$ & $4.67 \pm 1.09$ & 0.006 \\
\hline$C_{\max }(m g h L-1)$, plasma & $0.84 \pm 0.32$ & $0.57 \pm 0.13$ & 0.077 \\
\hline $\mathrm{CL} / \mathrm{F}, \mathrm{L} / \mathrm{h}$ & $42.51 \pm 12.02$ & $56.6 \pm 15.85$ & 0.029 \\
\hline Metformin in the urine, $\%$ of dosec, & $43.7 \pm 11.97$ & $43.05 \pm 6.1$ & NS \\
\hline
\end{tabular}

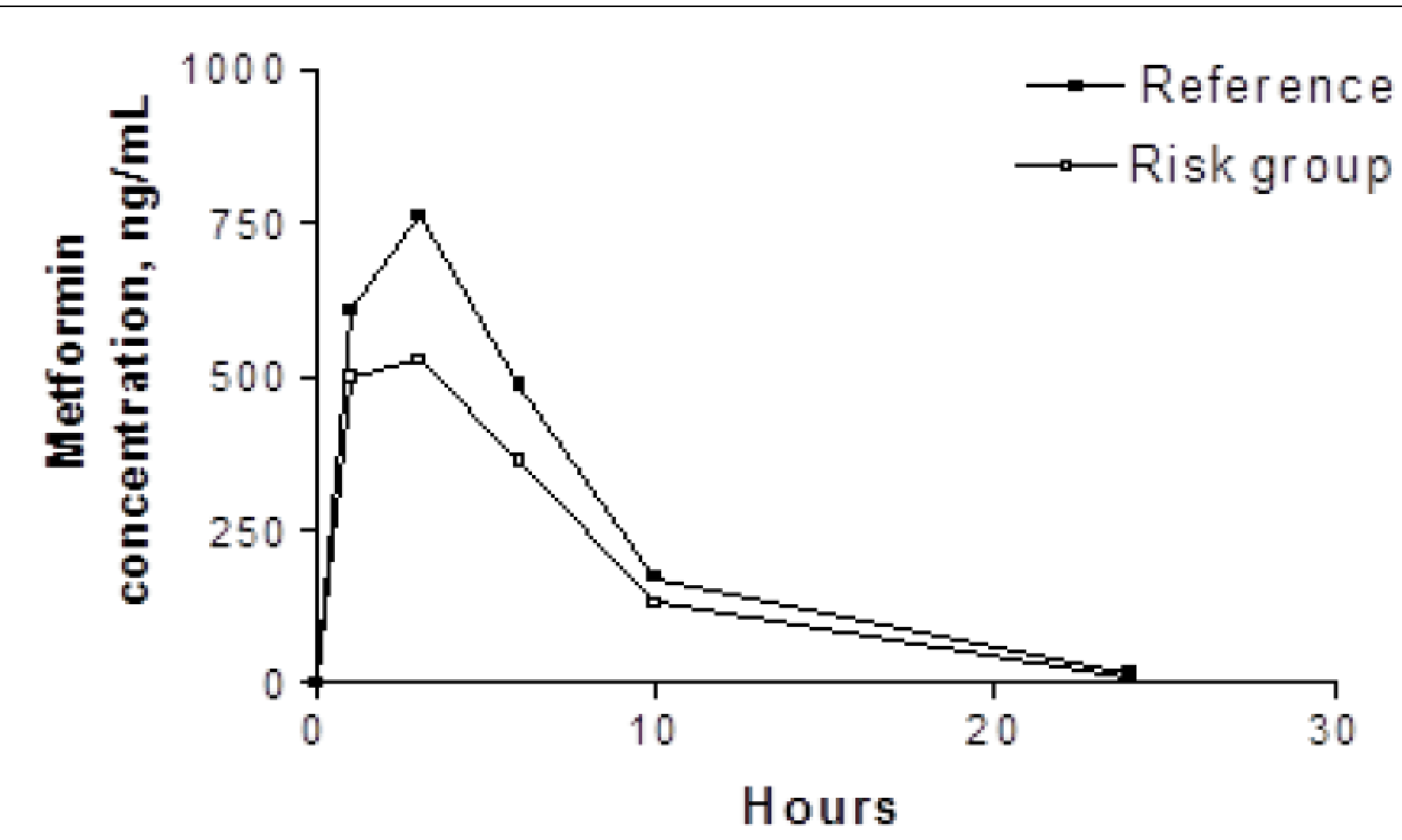

Figure 3. Difference in mean plasma metformin levels between groups

\section{Conclusion}

Using the dense genotyping of tagSNPs from 6 genes coding for solute carriers responsible for transport of the metformin we have identified for the first time the strong association of 3 SNPs in the $400 \mathrm{~kb}$ locus harboring SLC22A1, SLC22A2 and SLC22A3. Two SNPs are located in the $5^{\prime}$ flanking regions of the SLC22A2 and SLC22A3 while one SNP is located upstream of the SLC22A3. These SPNs may potentially be involved in the regulation of expression. Main advantages of the study are dense genotyping of the region and precise phenotyping of the patients including the well controlled and relatively short timing of the HbA1c measurement in which the potential influence of metformin transporter on the efficiency are the most prominent. Pharmacokinetic study in 15 healthy individuals confirmed association of polymorphisms with reduced systemic exposure to metformin. 